\title{
A atuação dos intérpretes de Libras com educandos surdos no ensino fundamental
}

\author{
Luiz Antonio Zancanaro Junior* \\ Tatiane Maria Lui Zancanaro**
}

\section{Resumo}

O presente artigo visa discutir a atuação do intérprete de Libras em sala de aula com educando surdos dos anos iniciais do ensino fundamental que possuem vocabulário escasso dos sinais do contexto escolar. Além disso, busca promover uma reflexão sobre a problemática envolvida. Para a fundamentação teórica, utilizaram-se as concepções apresentadas por Lacerda (2013). Para efetivação da pesquisa, as bases metodológicas utilizadas foram observação e questionário. Participaram da pesquisa quatro sujeitos, sendo dois professores regentes com formação em pedagogia e dois intérpretes educacionais que atuam no ensino fundamental da rede municipal de ensino de Itajaí. Os educandos surdos inseridos nesse contexto possuem um conhecimento de Libras considerado insuficiente, o que desfavorece sua aprendizagem e o processo de inclusão escolar. Terminadas as entrevistas, descreveram-se os resultados e posteriormente discutiram-se os dados coletados. O IE apoia o professor no planejamento das atividades e desenvolvimento de estratégias para a prática pedagógica priorizando os recursos visuais. Cabe ressaltar que as atribuições do intérprete são diferenciadas, pois se trata de mais um profissional em sala de aula para mediar a comunicação com o educando surdo, que às vezes, também assume uma pequena parte de professor regente.

Palavras-chave: Intérprete educacional; Língua Brasileira de Sinais; Educação inclusiva.

\footnotetext{
* Doutorando em Linguística pela Universidade Federal de Santa Catarina, Itajaí, Santa Catarina, Brasil.

** Especialista em educação de surdos pelo Instituto Federal de Educação, Ciência e Tecnologia de Santa Catarina, Itajaí, Santa Catarina, Brasil.
} 


\section{The action of the Libras interpreters to deaf students in primary school}

\section{Abstract}

This article aims to discuss the performance of LIBRAS interpreter in the classroom with deaf students in the early years of elementary school that have sparse vocabulary of the school context signals. In addition, it aims to promote a reflection on the issues involved. For the theoretical foundation, the conceptions presented by Lacerda (2013) were used. To execute the research, the methodological bases used were observation and questionnaire. Participants were four characters, two regent teachers graduated in pedagogy and two educational interpreters who work in elementary school in Itajaís municipal school system. Deaf students inserted in this context have LIBRAS knowledge considered insufficient, which disfavors their learning and the process of school inclusion. Completed interviews, the results were described and later the data collected were discussed. IE supports the teacher in planning activities and developing strategies for pedagogical practice prioritizing the visual aids. It must be emphasized that the interpreter assignments are different, because it is more of a professional in the classroom to mediate communication with the deaf student, who sometimes also plays a small part of regent teacher.

Keywords: Educational interpreter; Brazilian Sign Language; Inclusive education.

\section{Introdução}

O intérprete de língua de sinais é um profissional que desempenha uma importante função nos diversos contextos em que atua sendo eles educacionais ou não. Mediante isto é impossível falar de educação. Sem citar situaçóes específicas e delicadas que envolvem e compóem este tema. A presença desse profissional no ensino fundamental requer muitas reflexóes e cuidados, já que ele atua diretamente no processo de ensino-aprendizagem do sujeito surdo. A relevância da sua atuação se dá principalmente na mediação da comunicação entre surdos e ouvintes. Tendo em vista que a maioria das escolas inclusivas onde existe a presença de alunos surdos não há professores, alunos ou funcionários com fluência necessária para uma boa comunicação. Cabe ao intérprete a função primordial de fazer com que as relaçóes comunicativas aconteçam da melhor maneira possível.

No entanto, percebe-se que em algumas escolas municipais a presença desse profissional não garante um processo de ensino-aprendizagem satisfatório. Com isto, procurou-se investigar como este processo acontece e como se dá a atuação do intérprete educacional dentro da sala de aula, a fim de refletir sobre a efetiva relevância do seu trabalho. De acordo com Fernandes (2005) os indivíduos surdos estão inseridos na sua maioria em famílias ouvintes que tem a língua portuguesa como primeira língua em suas modalidades escrita e oral, em decorrência disto desconhecem a necessidade de oferecer a este sujeito a oportunidade de adquirir sua primeira língua, a Língua Brasileira de Sinais (Libras). Frequentam a escola comum onde o ensino é 
ministrado na língua portuguesa, e a minoria dos professores dominam a Libras, resultando assim no atraso da aquisição desta língua, pois não há o compartilhamento das duas línguas (Libras e português) desde a infância, não atendendo as principais recomendações modelo, já que a mera presença do intérprete de Libras não garante a aprendizagem.

A rede municipal de ensino de Itajaí conta com a atuação de cinco profissionais surdos, instrutores de Libras, que estão presentes em diferentes contextos. Além de realizarem o ensino da Libras como primeira língua nas escolas comuns que possuam alunos surdos matriculados. Bem como no contra turno através do atendimento educacional especializado (AEE), também oferecem o ensino de Libras como segunda língua, à comunidade, contemplando familiares, amigos ouvintes e profissionais da educação.

Por não ter o cargo do professor bilíngue (Língua portuguesa e Libras) esta função é realizada pelo professor do Atendimento Educacional Especializado (AEE), que tem conhecimento da língua da pessoa surda. Os profissionais tradutores/intérpretes de Língua de Sinais em sua maioria são servidores efetivos, há poucos contratados temporariamente.

Para que a pesquisa se apresentasse consistente foram realizadas visitas de campo em duas unidades escolares públicas no município de Itajaí-SC com o intuito de observar a atuação dos intérpretes educacionais que possuem fluência na Libras. Também foi possível observar que alguns alunos surdos não dominam satisfatoriamente a Libras que é o meio de comunicação que permite que ocorra efetivamente um processo ensino-aprendizagem de qualidade, bem como uma comunicação expressiva e compreensiva para garantir um desenvolvimento pleno e satisfatório.

A questáo do ensino de Libras pelo intérprete dentro da escola é uma problemática, pois sua função é interpretar/traduzir para a língua portuguesa o que o surdo sinaliza em Libras e/ou interpretar/traduzir para a Libras o que o professor e os alunos ouvintes falam/escrevem em português. Porém, muitas vezes acontece o fato do intérprete educacional realizar aulas ou cursos de Língua de Sinais dentro da escola para os alunos, professores, pais e funcionários, talvez o profissional assuma outras atividades e funçôes que não lhe caberiam, porém ele não deixa de exercer a interpretação, que é sua real atividade, no contexto escolar.

O presente artigo está organizado da seguinte forma: primeiramente oferece uma abordagem referencial teórica relatando a atuação do intérprete educacional na sala de aula. Posteriormente, é realizada uma explanação a respeito do desenvolvimento metodológico da pesquisa e depois uma breve discussão e análise dos resultados com o intuito de finalmente, concluir como se dá a atuação do intérprete educacional em sala de aula, e como acontece a relaçáo entre este profissional e o educando surdo que possui uma Língua de Sinais insuficiente ou com pouca fluência e conhecimento para uma aprendizagem escolar satisfatória, pois este sujeito está em processo de aquisição da Libras. 
Este artigo objetiva promover uma reflexão embasada na problemática que foi observada na atuação do intérprete educacional e sua relação com o professor regente em sala de aula e com os educandos surdos que apresentam um escasso vocabulário de sinais no contexto escolar dos anos iniciais no ensino fundamental, ressaltando que os intérpretes educacionais e os professores devem trabalhar de maneira conjunta, para que o aluno surdo possa aprender a Libras, bem como os demais conteúdos curriculares.

\section{Intérprete educacional como mediador na sala de aula}

Em alguns países como EUA, Canadá, Austrália, entre outros, tem-se utilizado o termo "intérprete educacional" (IE). Há uma preocupaçáo em diferenciar os profissionais intérpretes que atuam no espaço educacional, daqueles que atuam em outras esferas. Na Itália, o profissional que atua no espaço escolar não é chamado intérprete, mas de auxiliar de comunicação. Especialmente, o intérprete educacional deve versar conteúdos da língua portuguesa para a língua de sinais do seu país e viceversa, para favorecer a aprendizagem por parte do aluno surdo (LACERDA, 2013).

O educando surdo em sala de aula pode apresentar dificuldades de aprendizagem dos conteúdos e de alguns conhecimentos.

O IE tem como atribuição intermediar as relaçóes entre o aluno surdo e a comunidade escolar que inclui os professores regentes e demais alunos ouvintes. Ele deve estabelecer uma relação de parceria com o professor, assumindo o compromisso de preparar as atividades adaptadas com recursos visuais, sendo assim o ensino dos conteúdos desenvolvidos será realizado pelos professores que utilizarấo as adequaçóes do intérprete e as estratégias da prática pedagógica, sendo um apoio aos professores regentes, que por sua vez têm autoridade absoluta na sala de aula, e que garantem a qualidade da sua atuaçáo durante as aulas que favoreçam a aprendizagem do educando surdo podendo contribuir no aprimoramento do desenvolvimento deste educando. Contudo, isto pode evitar prejuízos na linguagem e na inadequaçáo do nível de aprendizagem. De acordo com Pires e Nobre:

O ILS em sala de aula intermediando as relaçóes entre professor/ aluno surdo, aluno ouvinte/aluno surdo nos processos de ensino/ aprendizagem tem grande responsabilidade. Além dos conhecimentos necessários para que sua interpretação evite omissóes, acréscimos ou distorçôes de informaçóes de conteúdo daquilo que é dito para a Língua de Sinais, ele deve atento às apreensôes feitas pelos alunos surdos e aos modos como eles efetivamente participam das aulas. Muitas vezes, é a informação do IE sobre as dificuldades ou facilidades dos alunos surdos no processo de ensino/ aprendizagem que norteia uma açáo pedagógica mais adequada dos professores. (PIRES; NOBRE, 2004, p.34 apud LACERDA, 2013).

Isto não significa que o intérprete está assumindo o papel do professor regente e sim auxiliando no processo de desenvolvimento do aluno surdo, pois o professor regente tem como responsabilidade solicitar ao intérprete educacional informaçôes 
a respeito do desenvolvimento do aluno. Os educandos surdos recém-iniciados no ensino fundamental apresentam uma dificuldade maior em compreender que o intérprete educacional é um profissional que está inserido na sala de aula apenas para transmitir da língua falada (português) para a língua do aluno (Libras), que é apenas um intermediador na relação entre professor e educando.

Entre surdos e ouvintes há limites de comunicação por causa da falta dos profissionais. Os surdos ficam em prejuízo ao receber as informaçóes na língua oral e não se é transmitido para a sua língua, resultando em prejuízo na participação de várias atividades. Esta problemática desestimula o educando realizar as atividades, em virtude da falta de acesso ou a total omissão das informaçóes.

A mesma autora ressalta que o papel de um intérprete em sala de aula se diferencia de algumas situaçóes em outros ambientes:

[...] A atuação do intérprete em sala de aula é bastante diferente daquela de um intérprete em uma conferência, ou em uma consulta médica, variando de acordo com os níveis de ensino assistidos (SHAE; JAMIESON, 1997; ANTIA; KREIMEYER, 2001; LACERDA, 2003; KELMAN, 2005).

Tais estudos focalizam que a atuação no espaço educacional tem características próprias que precisam ser respeitadas e não se trata de respeitar ou não o código de ética, mas de compreender os diferentes contextos e as necessidades que cada um deles impóe para a atuação do ILS. (LACERDA, 2013, p. 29).

As pesquisas sobre os intérpretes de Libras em sala de aula no Brasil apenas vem retratando a realidade que hoje vivenciamos, sem sugestôes de mudanças reais. Outra questão é que essas mudanças são muitas complexas, ou seja, não dependem apenas do professor ou do IE, mas de toda organização do sistema escolar. A forma de atuação deste profissional ainda tem caráter experimental em muitas realidades, Lacerda (2000 apud Lacerda, 2013) fez um estudo e pesquisou a questâo em relaçáo ao intérprete com ênfase na educação. Quando há a presença de um intérprete de língua de sinais em sala de aula, é porque o aluno surdo tem direito de garantir a sua diferença linguística, ou seja, recebe a informação escolar na língua de sinais. $\mathrm{O}$ professor regente ministra a aula sem se preocupar em como os sinais seráo passados, apenas atuando em sua língua de domínio não se preocupando com a língua principal do aluno surdo, porém, é necessário que sejam dadas oportunidades para que os educandos surdos possam se desenvolver e adquirir a construção de um novo conhecimento satisfatório.

É importante que a Língua de Sinais seja conhecida pelo professor regente da classe, o intérprete tem como responsabilidade conhecer a língua de sinais objetivando a comunicação com os alunos surdos, já a responsabilidade pela educação do aluno surdo, não deve ser somente do interprete, pois este busca a parceria, do professor regente e ambos planejam as atividades em sala de aula, por razóes da falta de uma língua comum entre o professor ouvinte e o aluno surdo podem ocasionar limites de um processo educativo, trazendo uma certa dificuldade para a relação do aluno no desempenho e participação em sala de aula, já que não podem se relacionar direto 
com seu professor pois este não é conhecedor da sua língua. A proposta bilíngüe fica comprometida, pois muitas vezes, o aluno surdo sem iniciativa, não dá atenção ao professor ouvinte, porque este não sabe Libras e ao mesmo tempo o aluno se sente desvalorizado, e o IE passa a ser uma figura de referência, mas sem autoridade em sala de aula. No espaço escolar a Libras precisa acontecer livremente e por esta razáo o professor precisa desta língua. Ao serem ministrados os conteúdos, o intérprete educacional atua, porém se o aluno tem dúvidas em alguma questão, ele espera que o professor possa atendê-lo, é um direito do aluno solicitar a ajuda do intérprete educacional somente se necessário (LACERDA; LODI, 2006 apud LACERDA, 2013).

\section{Metodologia}

Esta pesquisa apresenta um caráter qualitativo, pois é um estudo que se propôs a observar e identificar uma questâo muito importante que é a atuação do intérprete educacional e do professor regente em sala de aula. Pesquisa esta realizada em duas escolas específicas do município de Itajaí do estado de Santa Catarina. Para a seleção dos participantes desta pesquisa adotou-se como critério alguns pontos tais como: que os professores regentes e os intérpretes educacionais atendessem aos educandos surdos, onde os mesmos apresentassem a aquisição de Língua de Sinais de forma tardia sendo assim insuficientes na comunicação da sua língua, ou seja, estấo em processo de aquisição da mesma.

Foi realizada uma visita a campo na sala de aula inclusiva, na escola regular municipal para observar como a criança surda se relaciona com o IE e com o professor regente, que ministra várias disciplinas. Esta observação identificará como está o processo de aquisição e desenvolvimento da linguagem do educando surdo.

Os participantes desta pesquisa foram quatro sujeitos, sendo dois professores regentes com formaçáo superior em pedagogia e dois intérpretes educacionais. $\mathrm{O}$ professor regente 1, é acompanhado pelo IE 3, que está cursando pedagogia. Quanto ao professor regente 2 , este é acompanhado pelo intérprete 4, que já concluiu sua formação também em pedagogia.

Os educandos surdos envolvidos na pesquisa, atendidos pelos profissionais mencionados, tem idades entre 8 e 9 anos e seus pais são ouvintes. Estão matriculados no $3^{\circ}$ ano do ensino fundamental, recebem apoio de um professor surdo de Libras na escola além do atendimento educacional especializado no contraturno escolar.

Elaboraram-se perguntas com o intuito de compreender a relação entre os professores regentes e os intérpretes educacionais, e quais as intermediaçóes com os educandos surdos contribuindo no desenvolvimento da sua linguagem e na sua aprendizagem. Foram entregues questionários com respostas abertas elaborados por meio de escrita do português aos professores regentes e os intérpretes educacionais. Estes realizaram a atividade em 45 minutos. Após do término da entrevista com os 
participantes realizou-se a discussão dos resultados.

\section{Discussões dos resultados}

Para que a presente pesquisa se mostrasse consistente foram visitadas duas unidades escolares públicas no município de Itajaí do estado de Santa Catarina. Observou-se os IEs que possuíam fluência na Libras, porém percebeu-se que os educandos surdos entendiam pouco o que era sinalizado, uma vez que não dominam a estrutura da língua de sinais. Exemplifico uma das situaçôes: o intérprete educacional fez um desenho e o mostrou ao educando surdo, foi perceptível que esta adaptaçáo visual facilitou no entendimento e na comunicação, pois o IE aproveitou esta estratégia para ensinar um novo sinal. Por outro lado, os professores regentes nas turmas inclusivas conheciam um pouco a língua do educando surdo. Realizavam qualquer tipo de comunicação possível, como mímica e gesto para favorecer o entendimento.

Os professores regentes responderam a questão 1: Ao se comunicar com alunos surdos, você utiliza outros tipos de linguagem? Qual?

Professor regente 1: "Comunicação oral e gesticulo". Tem a intérprete, mas a aluna não conhece muitos sinais em Libras, por isso falamos e gesticulamos".

Professor regente 2: "Linguagem gestual. Estou aprendendo a me comunicar com o educando. Algumas coisas são compreendidas e outras não, tanto por mim quanto pelo educando".

Os professores regentes acompanharam em frente ao educando surdo durante as atividades, bem como tentaram ter uma conversa para descobrir o limite de comunicação. O educando não entendia os sinais, a professora regente tentou realizar a comunicação através de gestos, que é uma estratégia de auxílio que facilita no entendimento do educando. No caso da professora regente que não conhecia a língua de sinais existia somente o profissional intérprete educacional contratado na sala de aula inclusiva, pois a professora acabara de assumir a turma.

Alguns educandos surdos não dominam a língua de sinais, tendo em vista que os pais são ouvintes e também não conhecem a língua, ou seja, falta-lhes o contato com sua língua natural, ocasionando assim, atraso na linguagem. Os pais procuraram a orientação na comunidade escolar, levaram o educando surdo no centro de atendimento educacional especializado (AEE) no contraturno, que possui um profissional surdo que ministra a língua de sinais na minoria linguística, desta forma, tiveram acesso de forma tardia ao $\mathrm{AEE}$, pois as escolas náo possuem encontro entre adulto e criança surda. Elas encontram os surdos adultos na fase da adolescência. Salienta-se que é necessário o encontro de pessoas com as mesmas características, segundo Perlin:

É uma identidade subordinada com o semelhante surdo, como muitos surdos narram. Ela se parece a um imã para a questão de identidades cruzadas. Esse fato é citado pelos surdos e particularmente sinalizado por uma mulher surda de 25 anos: aquilo no momento de meu encontro com os outros surdos era o igual que eu queria, tinha a comunicação que eu queria. Aquilo que iden- 
tificavam eles identificava a mim também e fazia ser eu mesma, igual. O encontro surdo-surdo é essencial para a construção da identidade surda, é como abrir o baú que guarda os adornos que faltam ao personagem. (PERLIN, 1998, p. 58).

Os intérpretes educacionais responderam a questão 2: Quando o educando não domina Libras e quais as estratégias utilizadas?

Intérprete educacional 3: "adaptação com materiais de apoio visual, e procuro usar os sinais mais básicos, e muito classificador".

Intérprete educacional 4: "Peço uma visita de uma profissional do Centro Atendimento de Educação Especial para saber como proceder com devido aluno".

Conforme a Lacerda (2013), muitas vezes o conhecimento dos alunos surdos é insuficiente e o intérprete precisa ensinar certos sinais, ou colaborar para a construção de conceitos para que os alunos surdos acompanhem os conteúdos trabalhados. Sendo assim, o IE assume parcialmente o papel de professor a medida que auxilia o aluno na aprendizagem e desenvolvimento de sua língua.

$\mathrm{Na}$ questão seguinte, perguntava-se: se os educandos possuem a Libras insuficiente como é possível adquirir os conteúdos do conhecimento na vida escolar, na prática pedagogia, na adaptação de um método visual para as pessoas surdas? Teve algum auxílio do profissional da educaçáo (professor ou intérprete educacional) para preparar as atividades adaptadas?

Professor regente 1: "Não, mas não é realizado com o educando".

Professor regente 2: "Sim é necessário adaptação curricular, educação inclusiva e bilingue".

Intérprete educacional 3: "Tento adaptar, mas é difícil pela falta de tempo, como não possuo hora atividade fica praticamente impossivel".

Intérprete educacional 4: "Sim, junto com a professora regente sempre que necessário".

Neste sentido, a instituição não possui material adaptado para trabalhar com as crianças surdas, como livros, jogos que utilizam o alfabeto, números e sinais em Libras, sendo somente as adaptaçōes do professor com seus materiais e conteúdos utilizando recursos visuais como imagens que favorecem a aprendizagem do educando surdo. É inegável como os professores percebem a mudança no seu ensino e na sua prática com a presença dos educandos surdos, bem como náo existem adaptaçôes curriculares necessárias para a inclusão do surdo na unidade escolar, como a utilização de mais recursos visuais.

Este é considerado um momento muito difícil, pois o professor regente 1 não possui formação ou capacitação em educação especial, sendo que ela se assustou ao receber o educando surdo. Ele não prepara com antecedência os conteúdos que serão ministrados com uso de materiais visuais para ensinar o aluno surdo. Quando passou 
a ter a presença do intérprete educacional na turma inclusiva, o professor começou a tratar o intérprete somente como assistente que fazia a interpretação durante as aulas, sendo que ela não tinha direito a nada, nem a dar opiniáo de como trabalhar melhor o conteúdo e de como ele poderia ser adaptado de forma mais acessível para um educando surdo. Percebeu-se que a intérprete educacional tem muita dificuldade de se relacionar com a professora regente por causa da falta de parceria.

De acordo com Lacerda (2013), é relevante que o intérprete esteja preparado para atuar no meio educacional também como educador, para atender inclusive as relaçôes linguísticas mais peculiares, auxiliando na construção do conhecimento. $\mathrm{O}$ papel do intérprete não é o de substituir o professor regente. Deve ficar claro que o professor regente é responsável por planejar as aulas, por decidir qual conteúdo é adequado, pelo desenvolvimento e pela avaliação dos alunos em sala de aula, mas o intérprete educacional conhece bem os alunos surdos e a surdez e, com isto, pode colaborar o professor sugerindo atividades.

Da mesma maneira, é importante que o IE planeje junto com o professor regente responsável pela disciplina, respeitando a sua atuação e os seus limites no trabalho feito. O IE pode procurar estratégias e possibilitar adaptaçóes dos recursos visuais na prática pedagógica favorecendo uma melhor aprendizagem do educando, facilitando o entendimento da língua de sinais, como parceiro do professor.

Contrastando esta realidade, os intérpretes educacionais não auxiliaram os professores na elaboração da atividade prática, em decorrência do que foi respondido nos questionários: "falta tempo e a sala possui muitos alunos". Considera-se importante esse auxilio, pois os professores em geral não sabem trabalhar com alunos surdos e precisam de orientação. Também os intérpretes educacionais não têm conhecimento prévio dos conteúdos que serão trabalhados, o que se faz necessário, porque devem acompanhar toda a atividade que o educando têm direto, mediando a comunicaçáo com os ouvintes na comunidade escolar.

A questão do ensino de Língua de Sinais é uma polêmica para o profissional intérprete educacional. Sua função é de traduzir da língua fonte para a língua alvo na comunidade escolar, isto é, o intérprete deve acompanhar o educando surdo auxiliando na comunicaçáo com os sujeitos ouvintes na sala de aula, no pátio e em outros lugares onde ocorre interaçáo com os educandos e demais atores nas turmas inclusivas. No entanto, percebeu-se que o educando surdo também é desconhecedor da língua de sinais, por isso, é possível que o intérprete educacional tenha que ensinar os sinais aos educandos para que ele inicialmente aprenda a sua própria língua para então compreender os conteúdos.

Quanto à questão do papel do intérprete educacional, este é um campo complexo e bastante trabalhoso, sendo uma discussão que ainda não está clara conforme uma concepção. De acordo com Lacerda (2013) existem diversas atividades em que participam os intérpretes, buscando informaçóes sobre o conhecimento e fazendo a tradução. Entre muitas outras formas de interação dentro do contato cotidiano com o aluno surdo na sala inclusiva, o papel do profissional tradutor intérprete não expressa clareza por parte do próprio intérprete, bem como para os professores. O trabalho, 
muitas vezes se mostra pouco produtivo, porque se desenvolve de forma insegura, com falta de confiança e certos desconfortos.

As relaçôes entre os professores e os intérpretes educacionais são bem definidas, mas nos anos iniciais o trabalho ainda é bastante confundido com o de agente educacional, porque os educandos estáo iniciando a aquisiçáo da Língua de Sinais, parecendo que o intérprete educacional transmite apoio na forma como trata os educandos. Quando o intérprete chega na sala de aula o professor praticamente coloca a responsabilidade de alfabetização para o intérprete educacional.

\section{Considerais finais}

Este trabalho buscou compreender a construção de conceitos sobre o intérprete educacional a partir da interaçáo com o professor regente em sala de aula, considerando que num primeiro momento há dificuldade de entender o papel do intérprete de Libras na área da educação. O presente trabalho mostrou a importância das atividades no quesito interpretaçáo a qual contribuirão na ampliação do conhecimento, do real papel dos intérpretes educacionais e como esses agentes participantes e ativos na inclusão dos educandos surdos percebem a mudança na prática do seu trabalho, diferenciando a sua funçáo de um profissional intérprete que atua em outras áreas. Deve-se compreender que a área de educaçáo favorece o apoio da pedagogia e a adaptaçáo de conteúdos beneficiando aos educandos surdos o processo de aprendizagem na inclusão escolar. Algumas citaçóes de Lacerda comprovam a relaçáo com a pesquisa desse trabalho.

Alguns profissionais, tradutores intérpretes de Libras, manifestam pouco interesse de exercitar suas atividades nos anos iniciais do ensino fundamental, pois os educandos surdos ainda são insuficientes na Libras. Entretanto, acredita-se que são atividades totalmente distintas a interpretação/tradução nos anos iniciais levando em conta o nível da Língua de Sinais do educando. Os intérpretes têm dúvidas se devem ensinar alguns sinais corretos, ocasionando a insegurança quanto aos sinais incorretos, náo têm tempo de planejar as atividades, de utilizar estratégias pedagógicas, ou seja, de fazer adaptaçóes com a parceira do professor regente. O intérprete acaba acompanhado o educando em todas as horas, inclusive no intervalo, na educação física, nas aulas de artes e entre outros. Porém este profissional precisa de tempo para fazer as adaptaçóes das atividades, como por exemplo, pesquisar junto com o professor regente recursos e materiais visuais que apoiam a aprendizagem do educando surdo, oferecendo assim ao educando mais competência na Língua de Sinais.

O papel do IE e do professor é uma questáo que perpassa a organização escolar e a proposta curricular, haja vista que o ideal seria a grade curricular dos anos iniciais do ensino fundamental incluir a Libras como disciplina. A circunstância do surdo não ser fluente em Língua de Sinais não seria um problema tão grave se a escola tivesse uma estrutura para ensinar a Língua de Sinais como primeira língua e com a presença de professores surdos e bilíngues.

É fundamental incluir no currículo a disciplina de Libras desde o maternal, para que diminuam as dificuldades dos intérpretes educacionais e haja uma melho- 
ra no processo ensino-aprendizagem dos educandos surdos. Poderia ser proposto às escolas que possuem salas de aula inclusivas com alunos surdos, a implementação da Libras como disciplina curricular, da mesma forma que se tem a língua inglesa por exemplo, ampliando as possibilidades de comunicação e interação da pessoa surda, evitando prejuízos no processo de aquisição da linguagem.

É digno lembrar que os profissionais que se deparam com esta atual situação de inclusão se preocupam e tentam fazer o melhor que está ao seu alcance, porém, o melhor não é o ideal. É necessária uma organização primeiramente no sistema educacional, que infelizmente não está previsto em documentos. Em decorrência disto não conseguem oferecer aos educandos surdos o que eles realmente necessitam. É primordial o ensino da Libras como primeira língua para os surdos, e como segunda língua para os ouvintes, inserindo assim no âmbito escolar a cultura surda que hoje é pouco difundida. Porém, para que isto ocorra de modo eficiente, é preciso que haja profissionais habilitados e um empenho significativo da comunidade escolar.

É fundamental que os profissionais envolvidos nesse processo tenham clareza dos papéis e que professor regente e intérpretes estabeleçam e estreitem cada vez mais laços de união e cooperação, favorecendo a aprendizagem da criança surda.

Esses papéis e seus conceitos continuarão a ser discutidos, pois se trata de mais um profissional inserido na sala de aula. Este conceito não acaba, pois ainda há limitações quanto à discussão. É importante reconhecer as responsabilidades de cada profissional, entender a opinião no espaço escolar e o intérprete educacional aprimorar sua língua de sinais, para elaborar a prática pedagógica mais adequada aos educandos surdos.

A inclusão de educandos surdos no ensino regular muitas vezes significa apenas criar vagas e dar poucos recursos materiais. Para almejar uma escola inclusiva e, consequentemente, uma sociedade inclusiva, tem-se que garantir o direito de aprendizagem, de igualdade e de oportunidades a todos os alunos. É necessário ter professores capacitados e compromissados com a educação de todos, mas alguns educadores sentem imensa dificuldade para ensinar o aluno surdo, principalmente na alfabetização, além de ocorrer o caso que o educando não sabe muitos sinais da Libras em virtude de seu histórico social, familiar, e escolar.

\section{Referências}

ANTIA, S. D.; KREIMEYER, H. The role of Interpreters in inclusive classrooms. American Annals of the Deaf, v. 146, n. 4, 2001, p. 355-365.

FERNANDES, E. Surdez e bilinguismo. Porto Alegre: Mediação, 2005.

KELMAN, C. A. Os diferentes papéis do professor intérprete. Espaço: Informativo Técnico-Científico, Rio de Janeiro, v. 24, p. 25-30, 2005.

LACERDA, C. B. F. Intérprete de Libras: em atuaçáo na educação infantil e no ensino fundamental. $5^{\circ}$. ed. Porto Alegre: Mediação, 2013.

LACERDA, C. B. F. O intérprete educacional de língua de sinais no ensino fundamental: refletindo sobre limites e possibilidades. In: LODI, A. C. B. (et al.) Letramentro e minorias, $2^{a}$ edição. Porto Alegre: Mediaçấo, 2003. 
PERLIN, G. Identidades surdas. In: SKLIAR, C. (Org.). A surdez um olhar sobre as diferenças. Porto Alegre: Mediaçăo, 1998.

SHAW, J.; JAMIESON, J. Patterns of classroom discourse in an integrated: interpreted elementary school setting. American Annals of the Deaf, v. 142, n. 1, 1997, p. 40-47

\section{Correspondência}

Luiz Antonio Zancanaro Junior - Prefeitura Municipal de Itajaí, Centro Municipal de Educação Alternativa de Itajai. Rua Alfredo Trompowski, Centro, CEP: 88303-140 - Itajaí, Santa Catarina - Brasil.

E-mail: juniorlz18@gmail.com - tatylui5@hotmail.com

Recebido em 21 de abril de 2015

Aprovado em 09 de outubro de 2015 